\title{
RELATIONSHIPS BETWEEN LAND USE/LAND COVER AND LAND SURFACE TEMPERATURE IN TABRIZ FROM 2000 TO 2017
}

\author{
Amir Tahooni ${ }^{1}$, Ata Abdollahi Kakroodi ${ }^{1, *}$ \\ ${ }^{1}$ Department of GIS and Remote Sensing, Faculty of Geography, University of Tehran, Tehran, Iran - \\ (amir.tahooni, a.a.kakroodi)@ut.ac.ir
}

KEY WORDS: land use/land cover, land surface temperature, Landsat, reflective roofs, urban heat island

\begin{abstract}
:
Urban Heat Island (UHI) refers to the development of higher urban temperatures of an urban area compared to the temperatures of surrounding suburban and rural areas. Highly reflective urban materials to solar radiation present a significantly lower surface temperature and contribute to reducing the sensible heat released in the atmosphere and mitigating the urban heat island. Many studies of the UHI effect have been based on Land Surface Temperature (LST) measurements from remote sensors. The remotely sensed UHI has been termed the surface urban heat island (SUHI) effect. This study examines Tabriz city land use/land cover (LULC) and LST changes using Landsat satellite images between 2000 and 2017. Maximum likelihood classification and single channel methods were used for LULC classification and LST retrieval respectively. Results show that impervious surface has increased $13.79 \%$ and bare soil area has decreased $16.2 \%$. The results also revealed bare soil class LST after a constant trend become increasing. It also revealed the impervious surface LST has a decreasing trend between 2000 and 2011 and has a little change. Using materials that have low absorption and high reflectance decrease the effect of heat island considerably.
\end{abstract}

\section{INTRODUCTION}

Urban Heat Island (UHI) effect is one of the ecological consequences of urbanization (Li et al., 2011). UHI refers to the development of higher urban temperatures of an urban area compared to the temperatures of surrounding suburban and rural areas (Santamouris, 2013). Increased urban temperature is the result of the positive thermal balance of cities caused by the additional heat released and stored in the urban structure, and the lack of low temperature environmental sinks (Santamouris, 2001). To counterbalance the temperature increase in the urban environment and reduce as much as possible its impact on energy and environment, advanced and efficient mitigation technologies have been developed and applied widely (Akbari et al., 2016). Highly reflective materials to solar radiation when used in the urban environment present a significantly lower surface temperature and contribute to reducing the sensible heat released in the atmosphere and mitigating the urban heat island (Doulos et al., 2004). At the global scale, implementation of reflective roofs and pavements over urban areas would induce a negative radiative forcing, which is equivalent to offsetting tens of billions tons of $\mathrm{CO} 2$ emission (Akbari et al., 2008, Akbari et al., 2012).

The UHI effect can be evaluated by both air temperature measurements and satellite LST measurements. The measurement of air temperature is performed either on a traverse through a city or by comparing temperatures from point measurements (Schwarz, Lautenbach, \& Seppelt, 2011). However, because of the sparse distribution of observation stations, a spatially continuous analysis is often difficult. To solve these problems, many studies of the UHI effect have been based on land surface temperature (LST) measurements from remote sensors. The remotely sensed UHI has been termed the surface urban heat island (SUHI) effect (Streutker, 2002; Voogt \& Oke, 2003).
One important advantage of using remotely sensed surface temperature is its wall-to-wall coverage of the urban area, explicitly revealing its spatial patterns, although it only provides an instantaneous measurement of temperature during the day (li et al, 2011). Therefore, LST derived from thermal infrared remote sensors has become one of the most commonly used indicators for heat island analysis (Shen et al., 2016). a number of satellite systems can retrieve thermal infrared LST information with a relatively fine spatial resolution. For example, the spatial resolution of the TM/ETM+/TIRS sensors onboard the Landsat-5-8 satellites is $60 \mathrm{~m}$ to $120 \mathrm{~m}$.

The main objective of this study is evaluation of UHI and effect of roof cover changes on UHI variations in Tabriz as one of the major industrial cities in Iran using of Landsat satellite images and VHR images.

\section{METHODOLOGY}

\subsection{Study Area}

Tabriz is industrial city in northwest of Iran which located between $46^{\circ} 06^{\prime}-46^{\circ} 30^{\prime} \mathrm{E}$ and $37^{\circ} 59^{\prime}-38^{\circ} 13^{\prime} \mathrm{N}$. and covers a total area of $250.56 \mathrm{Km}^{2}$. Tabriz experiences warm summers and cold winters, and has an average annual temperature of 12.2 ${ }^{\circ} \mathrm{C}$. It has an annual precipitation of $311.1 \mathrm{~mm}$, which mostly occurs in winter and spring. Due to the semiarid climate, bare soil is exposed between sparse vegetation cover. Dense vegetation coverage is limited to plains where surface water or ground water is available in the form of agricultural areas (Amiri et al., 2009). 

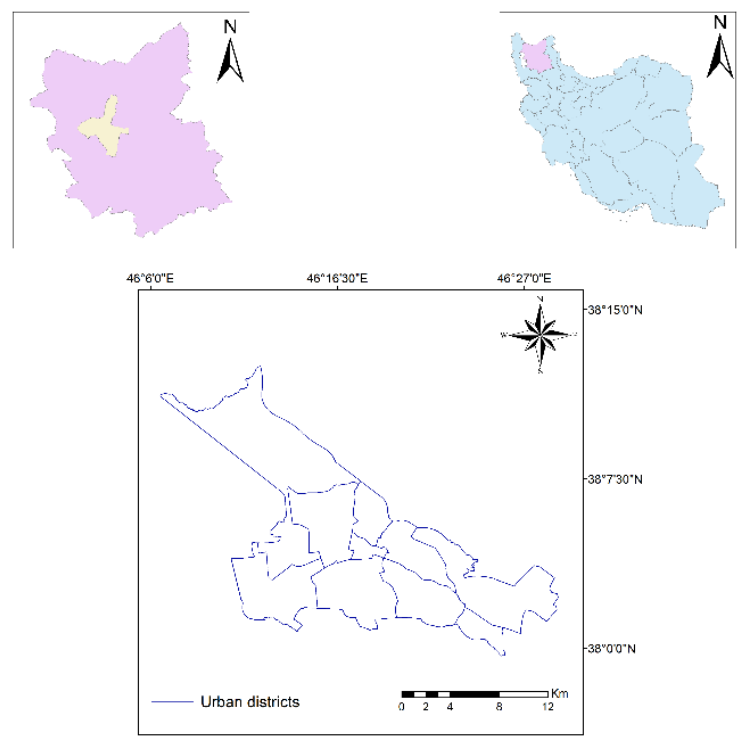

Figure 1. Study area

\subsection{Satellite images an image preprocessing}

Four cloud free Landsat 5 and 8 images downloaded from USGS site. All images were acquired in second half of the August month (table 1). Atmospheric correction applied to all images using FLAASH algorithm.

\begin{tabular}{|l|l|l|}
\hline Data & Acquisition date & TIR band spatial res. \\
\hline Landsat 5 TM & $2000-08-23$ & $120 \mathrm{~m}$ \\
Landsat 5 TM & $2006-08-24$ & $120 \mathrm{~m}$ \\
Landsat 5 TM & $2011-08-22$ & $120 \mathrm{~m}$ \\
Landsat 8 OLI/TIRS & $2017-08-22$ & $100 \mathrm{~m}$ \\
\hline
\end{tabular}

Table 1. The satellite data used in this research.

\subsection{LST retrieval}

There are several methods for LST retrieval from Landsat images. we used Jiménez-Muñoz et al single channel method. Brightness temperature was calculated using equation (1):

$$
T_{b}=\frac{k_{2}}{\operatorname{Ln}\left(\frac{k_{1}}{L_{s}}+1\right)}
$$

where $T_{b}$ is the effective at-sensor brightness temperature in Kelvin, $L_{S}$ is the spectral radiance at the sensor's aperture in $\mathrm{W} /(\mathrm{m} 2 \mathrm{sr} \mu \mathrm{m})$, and $k_{1}$ and $k_{2}$ are the pre-launch calibration constants. For Landsat $5 k_{1}$ is 607.76 and $k_{2}$ is 1260.56 . and for Landsat 8 band $10 k_{1}$ is 774.8853 and $k_{2}$ is 1321.0789 . LST was calculated using equation (2):

$$
L S T=\gamma\left[\varepsilon^{-1} *\left(\psi_{1} * L_{S}+\psi_{2}\right)+\psi_{3}\right]+\delta
$$

Where

$$
\begin{aligned}
& \gamma=\frac{T_{b}^{2}}{b_{\gamma} L_{s}} \\
& \delta=T_{b}-\frac{T_{b}^{2}}{b_{\gamma}}
\end{aligned}
$$

Where $\varepsilon$ is emissivity, $\psi_{1}, \psi_{2}$ and $\psi_{3}$ are atmospheric function components were calculated using MODIS 05 water vapor product. Finally $b_{\gamma}$ is 1256 , and 1324 for Landsat 5 and 8. Emissivity was calculated using below equations: If $0<\mathrm{NDVI}<0.2$, emissivity is 0.97 If $0.2<\mathrm{NDVI}<0.5$,

emissivity $=0.004 * p v+0.986$

If NDVI $>0.5$, emissivity $=0.99$

Where $p v=\left(\frac{N D V I-N D V I_{S}}{N D V I_{V}-N D V I_{S}}\right)^{2}$

Where $\mathrm{NDVI}_{S}$ is bare soil NDVI and equals to 0.2 and $N D V I_{V}$ is dense vegetation and equals to 0.5 .

NDVI for images was calculated using equation (7):

$$
N D V I=\frac{\rho_{N I R}-\rho_{R E D}}{\rho_{N I R}+\rho_{R E D}}
$$

where $\rho_{N I R}$ and $\rho_{R E D}$ are the reflectance values in the nearinfrared and red bands.

\subsection{Image classification and accuracy assessment}

The Land Use Land Cover (LULC) change resulting from the urban expansion over the past 17 years can be quantified by image classification and segmentation (Ding and Shi, 2013). Maximum likelihood method was used to extract LULC classes. four types of LULC including bare soil, impervious surfaces vegetation and water bodies considered for this study.

Assessment of classification accuracy is important in accurate quantification of change detection (Ding and Shi, 2013). Regions of interest, modelled using ENVI software, were used as reference data for different LULC types. Kappa coefficient and overall accuracy for different image data were calculated using the test samples to check the accuracy of the classification results.

\section{RESULTS}

\subsection{LULC change assessment}

Kappa coefficient and overall accuracy for 4 images shown on table 2.

\begin{tabular}{|c|c|c|}
\hline Image date & Kappa coefficient & Overall accuracy \\
\hline 23 August 2000 & 0.97 & $98.46 \%$ \\
24 August 2006 & 0.93 & $95.36 \%$ \\
22 August 2011 & 0.97 & $98.45 \%$ \\
22 August 2017 & 0.96 & $97.38 \%$ \\
\hline
\end{tabular}

Table 2. Image classification and accuracy assessment

Image classification results shown on table 3.

\begin{tabular}{|c|c|c|c|c|}
\hline image & Bare soil & $\begin{array}{c}\text { Impervious } \\
\text { surface }\end{array}$ & vegetation & Water body \\
\hline $\begin{array}{c}23 \text { Aug } \\
2000\end{array}$ & 6058.98 & 7842.33 & 2948.67 & 4.95 \\
& $(35.95 \%)$ & $(46.52 \%)$ & $(17.50 \%)$ & $(0.03 \%)$ \\
24 Aug & 4685.04 & 9190.08 & 2974.32 & 4.41 \\
2006 & $(27.80)$ & $(54.53 \%)$ & $(17.65 \%)$ & $(0.02 \%)$ \\
22 Aug & 44.50 & 9438.21 & 2962.08 & 2.70 \\
2011 & $(26.40 \%)$ & $(56.00 \%)$ & $(17.58 \%)$ & $(0.02 \%)$ \\
22 Aug & 3328.11 & 10164.6 & 3357.54 & 3.33 \\
2017 & $(19.75 \%)$ & $(60.31 \%)$ & $(19.92 \%)$ & $(0.02 \%)$ \\
\hline
\end{tabular}


Table 3. Area of the LULC types during the 2000-2017

The results show that bare soil area is decreased over 17 years and conversely impervious surface area during this period is increased. Vegetation area become unchanged, but in 2017 a significant increase has happened. The is because of increasing urban green space.

\subsection{LST spatial and temporal variations}

Average LST for four types of LULC is shown on table 4. (unit of temperature values is Celsius)

\begin{tabular}{|c|c|c|c|c|}
\hline image & Bare soil & $\begin{array}{c}\text { Impervious } \\
\text { surface }\end{array}$ & vegetation & $\begin{array}{c}\text { Water } \\
\text { body }\end{array}$ \\
\hline $\begin{array}{c}23 \mathrm{Aug} \\
2000\end{array}$ & 44.92 & 42.86 & 39.83 & 32.16 \\
\hline $\begin{array}{c}24 \mathrm{Aug} \\
2006\end{array}$ & 44.58 & 42.02 & 39.38 & 29.98 \\
\hline $\begin{array}{c}22 \mathrm{Aug} \\
2011\end{array}$ & 44.32 & 38.18 & 38.63 & 29.17 \\
\hline $\begin{array}{c}22 \mathrm{Aug} \\
2017\end{array}$ & 49.05 & 38.61 & 42.24 & 33.45 \\
\hline
\end{tabular}

Table 4. LULC types average LST

According to the table 4, the average temperature of bare soil for the years 2000, 2006 and 2011 almost has constant value. But in 2017 a significant increase was happened. The average temperature of impervious surface indicates a decreasing trend from 2000 to 2011 and temperature difference between 2011 and 2017 is not very high. For vegetation class for the years 2000, 2006 and 2011 the LST has little variations, while for 2017 temperature has increased by 3.61 degrees Celsius. This is due to increasing of urban green space in the mountains and surrounding areas.

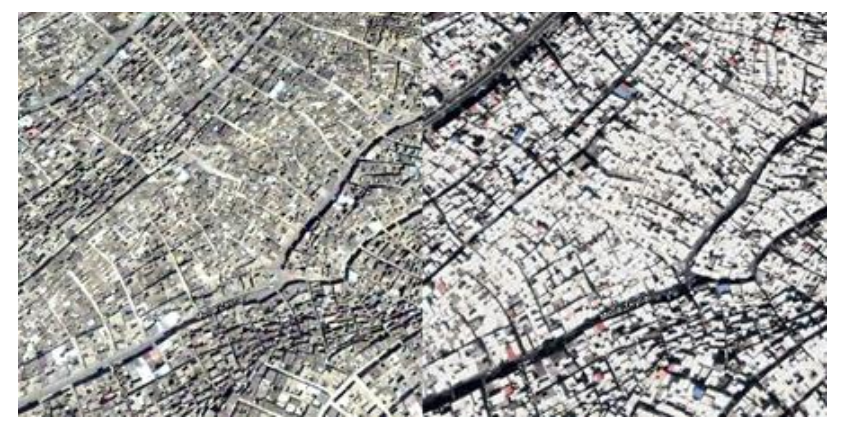

Figure 2. Urban roof covers change in 2000-2017

Fig 2 shows 2 images from same area of city. This part of city has very dense structure and the buildings are located at a very small distance to each other. Left side belongs to 2000 and right side belongs to 2017. As outlined in the Figure 2, roof covers changed to a high reflectance material which result in decreasing surface temperature.

\section{CONCLUSION}

In this study we used Landsat images and maximum likelihood classification method to assessment of Tabriz city LULC change over the 17 years monitoring. Also single channel method was adopted to LST retrieval. Results showed that over the 17 years the impervious surface area increased and bare soil is decreased. Also estimation of LST revealed that the average temperature of bare soil become unchanged values except for the year of 2017. The average temperature of impervious surface indicates a decreasing trend. Finally, covers changes from materials that have high absorption to materials that have low absorption and high reflectance has a great effect of decreasing urban heat island.

\section{REFERENCES}

Akbari H, Menon S, Rosenfeld A.,2008. Global cooling: increasing world-wide urban albedos to offset CO2. Clim Change 94:275-86.

Akbari H, Matthews HD, Seto D., 2012. The long-term effect of increasing the albedo of urban areas. Environ ResLett 7:024004

Akbari, H., Cartalis, C., Kolokotsa, D., Muscio, A., Pisello, A.L., Rossi, F., Santamouris, M., Synnefa, A., Wong, N.H., Zinzi, M., 2016. Local climate change and urban heat island mitigation techniques-the state of the art. J. Civ. Eng. Manag. $22(1), 1-16$.

Amiri, R., Weng, Q., Alimohammadi, A., Alavipanah, K., 2009. Spatial-temporal dynamics of land surface temperature in relation to fractional vegetation cover and land use/cover in the Tabriz urban area, Iran. Remote Sensing of Environment 113 2606-2617.

Ding, H., Shi W., 2013. Land-use/land-cover change and its influence on surface temperature: a case study in Beijing City, International Journal of Remote Sensing 34:15, 5503-5517.

Doulos, L., Santamouris, M., Livada, I., 2004. Passive cooling of outdoor urban spaces. The role of materials. Sol. Energy 77 (2), 231-249.

Jimenez-munoz, C., sobrino, J., Skokovic, D., Mattar, C., Cristobal, J., 2014. Land Surface Temperature Retrieval Methods from Landsat-8 Thermal Infrared Sensor Data. IEEE GEOSCIENCE AND REMOTE SENSING LETTERS, VOL. 11, NO. 10, OCTOBER 2014.

Jimenez-munoz, C., Cristobal, J., sobrino, J., Soria, G., Ninyerola, M., Pons, X., 2009. Revision of the Single-Channel Algorithm for Land Surface Temperature Retrieval from Landsat Thermal-Infrared Data. IEEE TRANSACTIONS ON GEOSCIENCE AND REMOTE SENSING, VOL. 47, NO. 1, JANUARY 2009339

Li, x., Song, c., Cao, L., Zhu, F., Meng, X., Wu, J., 2011. Impacts of landscape structure on surface urban heat islands: A case study of Shanghai, China. Remote Sensing of Environment 115: 3249-3263.

Santamouris M., 2013. Using cool pavements as a mitigation strategy to fight urban heat island-A review of the actual developments. Renewable and Sustainable Energy Reviews 26 224-240.

Santamouris, M., 2001. Energy and Climate in the Urban Built Environment. James and James Science Publishers.

Schwarz, N., Lautenbach, S., \& Seppelt, R., 2011. Exploring indicators for quantifying surface urban heat islands of European cities with MODIS land surface temperatures. Remote Sensing of Environment, 115: 3175-3186. 
Shen, H., Huang, L., Zhang, L., Wu, P., Zeng, C., 2016. Longterm and fine-scale satellite monitoring of the urban heat island effect by the fusion of multi-temporal and multi-sensor remote sensed data: A 26-year case study of the city of Wuhan in China. Remote Sensing of Environment 172: 109-125.

Streutker, D.R. 2002. A remote sensing study of the urban heat island of Houston, Texas. International Journal of Remote Sensing, 23: 2595-2608.

Voogt, J.A., Oke, T.R., 2003. Thermal remote sensing of urban climates. Remote Sensing of Environment, 86: 370-384. 